Regular Research Article

\title{
Seedling Recruitment of Native Tree Species in Active Restoration Forest
}

\author{
Yingluck Ratanapongsai ${ }^{1, *}$ \\ 1 Ph.D.'s Degree Program in Faculty of Science, Chiang Mai University, Chiang Mai 50100, Thailand \\ * Correspondence author: y.ratanapongsai@gmail.com
}

\begin{abstract}
Since the 1970's, concern has grown over the environmental impact of deforestation over large areas in the northern mountains of Thailand and conversion of forest to agriculture. Consequently, forest restoration has become an important strategy to achieve large-scale increases in forest habitat. The framework species method (FSM) of forest restoration has been adapted and developed to restore forest ecosystems on former agricultural land in northern Thailand. The method involves planting 20-30 forest species that are characteristic of the target forest ecosystem, and it relies on incoming native tree species, to sustain forest succession. However, little is known about recruitment of native tree species and the factors that limit it, during implementation of the FSM. The study compared recruited native tree species in the seedling community of FSM trial plots with nearby tree seed sources, to assess how many, and which, species successfully recolonize FSM plot seedling communities or fail to do so. The effects of seed-dispersal agent and seed size on recruitment was compared in FSM trial plots aged 6, 10, and 14 years. Approximately half of nearby native tree species were absent from the seedling community, across all 3 restoration ages. Seed availability was the major limitation of recruitment. Large-seeded species had a lower recruitment probability than small-seeded species did ( $P=0.0249$ (Tukey test)), whilst seed-dispersal agent had no effect $(P=0.42$ (Chi-square)). Recruitment rates were similar across all 3 restoration ages. Consequently, this study confirms that the framework species method is limited by availability of seed sources in the immediate vicinity of restoration sites. It is recommended that rare tree species, characteristic of the target forest ecosystem, and those with large seeds, should be added to the mix of framework tree species planted, science their natural colonization is unlikely. This would enhance species diversity and result in better restoration outcomes.
\end{abstract}

Keywords: Framework species; northern Thailand; seedling community; limited factors; seed dispersal; seed size

\section{Introduction}

Since 1970 's, deforestation in Thailand reduced overall forest area from $53 \%$ to $26.7 \%$ (Oberhauser 1997) and continuously lost 99,600 ha of forest annually from 1991 to 1998 (FAO, 2010). There was a concerning of environmental impact, especially in the northern mountains, an important water resource for main river in the Central Plain of Thailand. Deforestation and conversion of forest to agriculture is a major environmental problem, particularly in the upland water catchment areas, causing droughts, floods, landslides and contributing to global climate change (Oberhauser 1997). Thus, the Thai Forestry Department had been established and/or promoted many of forest restoration projects in a country-wide scale in attempt to increase forest area and ecological services (Oberhauser 1997; Kaewkrom et al. 2005; Koonkhunthod et al. 2007). Since 1997, the Chiang Mai University's Forest Restoration Research Unit (FORRU-CMU) has been studying and developing an active restoration technique called "framework species (FWS)" in order to applied on post-agriculture deforestation land of northern Thailand. The technique is adopted from the concept of 'Framework Species Method' (FSM) by Tucker and Murphy (1997) using a mixture of native species planted on cleared land to accelerate forest recovery. The framework species are selected from characteristic of the target forest ecosystem for 1) high rates of survival and growth (when planted out on exposed deforested sites), 2) dense spreading crowns that shade out weeds and 3) production of resources early in life (fleshy fruits, nectar-rich flowers etc.) that attract seed-dispersing animals (FORRU, 2005). The restoration begins with plantation of 20-30 native tree species, followed by a few years of post-planting treatment (weed cutting and fertilizer 
applying). After canopy closure begins, the rapid changes in environmental conditions facilitate germination of incoming tree seeds and early seedling establishment resulting in a return to natural forest dynamics (Tucker and Murphy 1997; FORRU 2005 and 2008; Sinhaseni 2008).

Intensity of land-use on deforestation lands such as agriculture influenced a sparse or lack of seed bank (Meers et al. 2012). Thus, the increasing of incoming native tree species (i.e. a species that was not among those planted species) is a major key for plant recovery to sustain natural forest succession process and biodiversity. The recruitment of native species is limited when species fail to reach and establish in suitable sites. Corett and Hau (2000) and Chazdon (2014) suggested that seed-dispersal controls forest recover in the secondary forest. In the restoration forest, planted trees play important part attracting animals into the restoration area providing more opportunity for seed reaching to the restoration area. Consequently, many of frugivorous birds were reported visiting the FWS trees leading to high density of animal-dispersed species seedlings under the planted trees (Wydhayagarn et al. 2009). Similarly, Viani et al. (2015) found a high density of animaldispersed tree seedlings under animal-dispersed trees and the proportion of those seedlings increased with plantation age which was similar to a finding by Tabarelli and Peres (2002). From seed source, size of seed influences mobility such as distance and dispersal agent. Small seeds are easily dispersed over long distances by the wind, birds, and mammals of a wide range of different body sizes, whilst, large seeds are rarely dispersed over long distances and need more specific dispersal-agents such as large animal (Corlett and Hau 2000). In the highlands of Ethiopia, bigseeded non-pioneer species are absent or rare in the understorey of restoration plots, whilst many small-seeded pioneer species are abundant (Eshetu, 2002). A study of seed dispersal in Doi SuthepPui National Park by Brodie (2007) found $80-95 \%$ of Choerospondias axillaris fruits, big-seeded species, was not dispersed, possibly due to the hunting that reduced wildlife populations. The declining of animal populations, as a result of deforestation, affect the population dynamics of animal-dispersed plant species (Corett and Hau 2000).

Plantations of native-tree species are often recommended for ecological restoration. The FWS restoration is also the technique that target on native species recovery. However, knowledge of seedling recruitment and factor limitation in the FWS restoration forest is still lack. Understanding of native species recruitment is needed to improve forest restoration technique. Therefore, this study addressed 3 questions about seedling recruitment of native tree species, 1) from seed source how much native species recruit in the FWS restoration forest, 2) do seed-dispersal agent and seed size influence the recruitment of native tree seedlings in the FWS restoration forest, and 3) can age of restoration forest influence the recruitment of native species in aspect of attracting more animaldispersed, big-seeded species seedlings. The study investigated recruitment of native species from the survey of adult tree species in the nearby natural forest as seed source and to compare to seedling community in 3 ages of active restoration by FWS technique. The recruitment rate of recruit seedlings and recruit native species were analysed to assess the effectiveness of the FWS technique attracting native tree species in the area.

\section{Materials and Methods}

\subsection{Study site}

The study site was established in the FWS restoration forest located above the village of Ban Mae Sa Mai village (BMSM), the Hmong hill tribe communities, $18^{\circ} 51^{\prime} 46.62^{\prime \prime} \mathrm{N}, 98^{\circ} 50^{\prime} 58.81^{\prime \prime} \mathrm{E}$, at 1200-1,400 meters above sea level (Figure 1-a). The average annual rainfall was ca. $1500 \mathrm{~mm}$. Low precipitation months $\left(<100 \mathrm{~mm} \mathrm{month}^{-1}\right)$ are November to March, about 5 months of a year, and the average annual temperature was $26.8^{\circ} \mathrm{C}$ from August 2012- April 2014, data collection period (data obtained from Northern Meteorological Centre (NMC) Chiang Mai province, 2012-2014). The restoration forest was once tropical evergreen forest dominated by indigenous tree species mostly in the Fagaceae, e.g. Castanopsis diversifolia and Castanopsis tribuloides. Parts of the mountain 
were cleared by villagers for agriculture activities. The forest area also supports 2,247 vascular plant species found in the area of which $21.6 \%$ are tree species (Maxwell \& Elliott 2001).

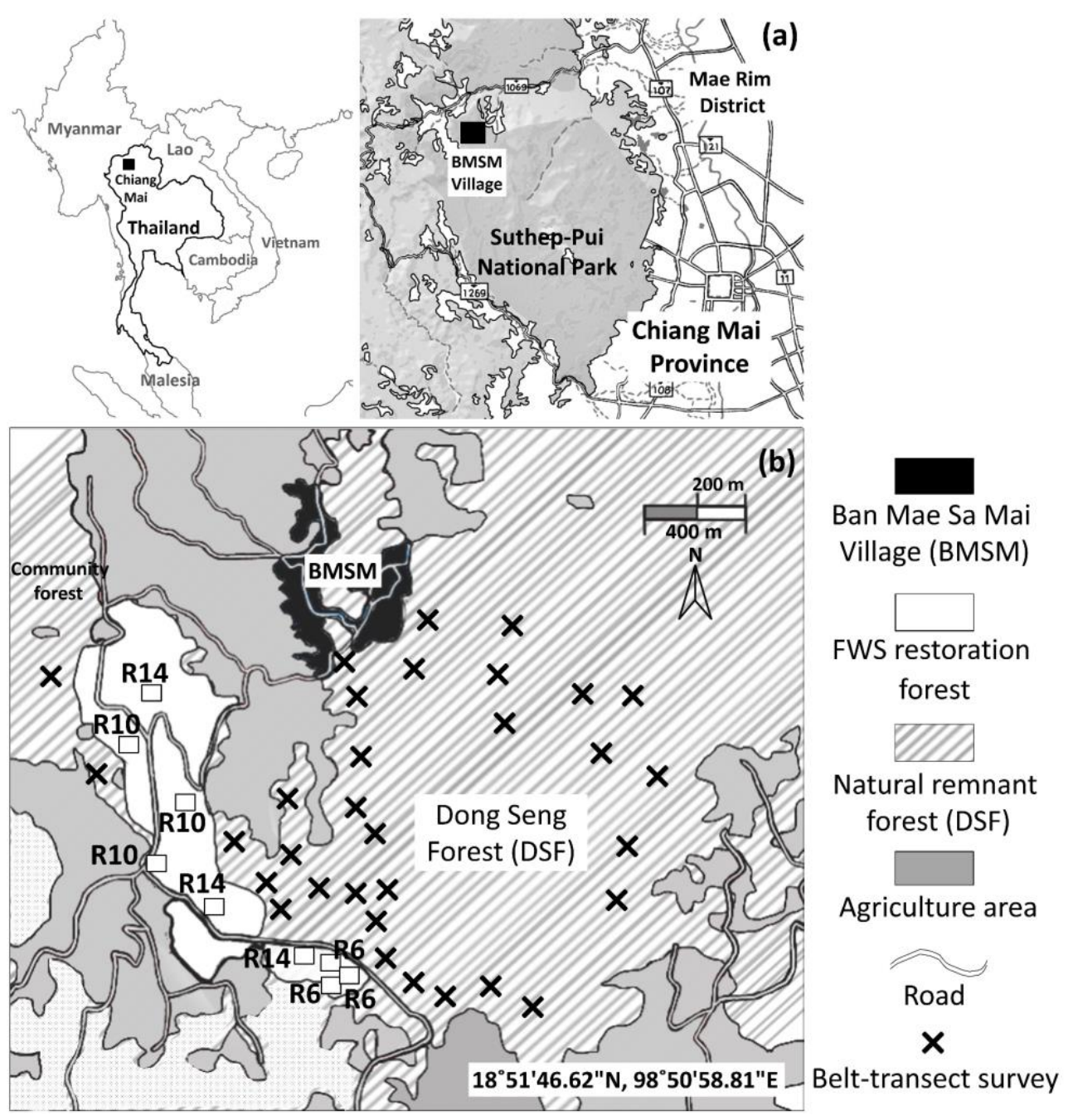

Figure 1. The study site: a) location of Ban Mae Sa Mai village, Mae Rim district, Chiang Mai, Thailand b) sample plots location in FWS restoration forests (R) surrounded by agriculture area, adult tree survey $(x)$ in natural remnant forest (DSF). (Source: Google maps)

\subsection{The FWS technique of forest restoration}

In Thailand, Chiang Mai University's Forest Restoration Research Unit (FORRU-CMU) has been studying and developing an active regeneration technique called "Framework Species" (FWS) for various forest types in Thailand and neighbouring countries, since 1994. The study aims to restore not only forest area but biodiversity and ecological service as well. The technique bases on the concept of framework species approach developed in Queensland, Australia by Tucker and Murphy (1997). Tucker and Murphy (1997) used a mixture of native species planting as frame to cover the deforestation area and accelerate forest succession. In Chiang Mai, Thailand, the FWS species were selected with 5 major characteristics suitable for restoring evergreen, seasonal forest (EGF) in northern Thailand (FORRU 2005; sensu Maxwell and Elliott, 2001). The characteristics consists of 1 ) high survival and growth rates, 2) broad, dense crowns to shade out herbaceous weeds, 3) produce fruits, nectar-rich flowers or other resources at a young age that attract seed-dispersal wildlife, 4) fire resilient, and 5) easy to propagate. After planting 20-30 framework species, post-planting 
process of weeding and fertilizer application were carried on for 2-3 rainy seasons (FORRU 2008; Elliott et al. 2003). A complete technique and guideline for the FWS restoration see FORRU (2005) (online available).

The FWS restoration site was established annually from 1997-2017 cover 33 ha and forms as a corridor along the mountain ridge link community forest to the Dong Seng Forest (DSF), a sacred forest of the villagers (disturbed primary forest, which had never been cleared for agriculture, but which had suffered minor disturbances being situated immediately adjacent to the village).

\subsection{Data collection}

For seedling community, three ages of FWS restoration forest were selected with 4 years interval from the oldest age sites, 14 years, to 10 years and 6 years sites (R14, R10, and R6 respectively). Circular ( $5 \mathrm{~m}$-radius) plots were set for seedling data collection, 12 sample plots each restoration age, set at least $5 \mathrm{~m}$ in from the edge of the $20 \times 20 \mathrm{~m}$-restoration site (FORRU 2005). For the purposes of this study, a tree seedling was defined as a woody stem $\geq 5 \mathrm{~cm}$-tall (or seedling with 2 true leaves) to $\leq 150 \mathrm{~cm}$-tall (excluding lianas, herbs, and shrubs). Every individual of native tree species (excluding planted species, lianas, herbs, and shrubs) was tagged with a metal label, identified to species level (following the species names of Maxwell and Elliott 2001) to classify for native tree species and planted FWS species. Dispersal agent and seed size were classified derived from literature: Maxwell and Elliott (2001), Ashton et al. (2001), the FORRU database, and online research (particularly The Flora of China (eFloras 2014)), while those species that were unable to classified were excluded from the analysis. The data collection was carried out from September, 2012 to April, 2014. It was started at the end of the wet season from September to October and dry season from March to April, over 4 seasons (2 years).

Adult trees $(\geq 10 \mathrm{~cm}-\mathrm{DBH})$ outside study plots were surveyed, counted, and identified for species in $100 \times 10 \mathrm{~m}$ belt-transects (Figure 1-b). The survey was established 16 belt-transects in the natural remnant forest (Dong Seng forest-DSF) and 16 transects in the natural patch forest outside the R forests. Data collection was carried out in February to April, 2014.

\subsection{Data analysis}

The species of tree seedlings establishing inside the restoration plots were compared with those represented by adult trees in the nearby old-growth forest and in the belt transects closer to the forest restoration plots. Species were then assigned to one of the following categories 1) recruit species-recorded in the seed tree survey and present in the seedling community (i.e. both effective seed dispersal and good conditions for seedling establishment); 2 ) absent species-recorded present in the seed tree survey but not found in the seedling survey (i.e. seed dispersal ineffective and/or poor conditions for seedling establishment); and 3) planted framework species and species the found as mother trees in the study plots which are not planted species but exist initially at the plantation was establish so they could act as the framework species as well). Species richness and diversity were calculated. The Whittaker $\beta$-diversity index was used to compare among communities. The population density of adult tree (individuals per ha) was calculated for each species, to compare the mean population density of adult trees between the recruited species and the absent species. The data set of native tree species seedlings was analysed for annual rate of recruitment over 4 censuses (Sheil and May 1996; Gomes et al. 2003) as

Equation (1) Recruitment Rate $(R \mathrm{c})=\left\{\left[\frac{\mathrm{N}_{0}+\mathrm{r}}{\mathrm{N}_{0}}\right]^{1 / \Delta \mathrm{t}}-1\right\} \times 100$

where $\mathrm{N}_{0}$ is the number of stems or species in the original population, $r$ is the number of recruited individuals or species, $\Delta$ t is time of the collection interval $\left(t_{1}-t_{0}\right)$. In this study, the analysed data from 
12 sample plots replication of each restoration forest age was calculate for mean and standard deviation. The statistical analysis was calculated to compare the data set as follows. The rates of recruitment were compared among sites by the Mann-Whitney test.

Every seedling was classified for seed-dispersal agent as 1) animal-dispersed species (refers to those that rely mostly on animals as seed-dispersal agents) and 2) non-animal-dispersed species (refers to those mostly dispersed by non-animal agents, such as by wind, water, or ballistics etc). The data sets were classified into for 3 seed-size classes as 1$)$ small $\left.\left(<2.2 \mathrm{~cm}^{3}\right), 2\right)$ medium $(2.2-20.2$ $\mathrm{cm}^{3}$ ) and 3) big $\left(>20.2 \mathrm{~cm}^{3}\right.$ ) (modified from Tabarelli and Peres (2002) integrating micro- and tinyseed size into one small size). Chi-square $\left(\chi^{2}\right)$ test and Tukey post-hoc test were used to compare the different proportion of seed-sizes and seed-dispersal agents among forest sites. The software "Paleontological Statistics version 3.0" was used to perform the statistical tests (Hammer et al. 2001; Hammer and Harper 2008).

\section{Results}

\subsection{Recruit and Absent of Native Tree Species}

Of total 208 species adult trees ( $\geq 10 \mathrm{~cm}-\mathrm{DBH}$ ) from 69 families, 49\% of them (101 species from 49 families) were not recorded (or absent species) in overall plots of the seedling community in the restoration $(R)$ forest, whilst, $51 \%$ of them (107 species) successfully established, and were recorded in seedling community of the R plots (Figure 2 and Table 1 ). The native species that recruit in the $\mathrm{R}$ plots was $28 \%$ to total adult species (59 species). Thirty-five species (17\%) established in the plots were species that had been planted, whilst 13 (6\% of total species) were derived from mature, nonplanted, seed trees (mother trees) that had initially existed in the $\mathrm{R}$ forest plots since before restoration commenced which was later on included in the planted species. Accordingly, the diversity of adult tree species was higher than recruited species of seedling community in the overall restoration plots (Table 1). Including seedlings of the FWS, the diversity declined from the low evenness due to a few dominate FWS species seedlings (unpublished data). However, the Whittaker $\beta$-diversity index indicates more similarity among adult species and the seedling community with overall species (recruited plus FWS species), at 0.4812 unit, than the recruited species alone, at 0.6434 unit.
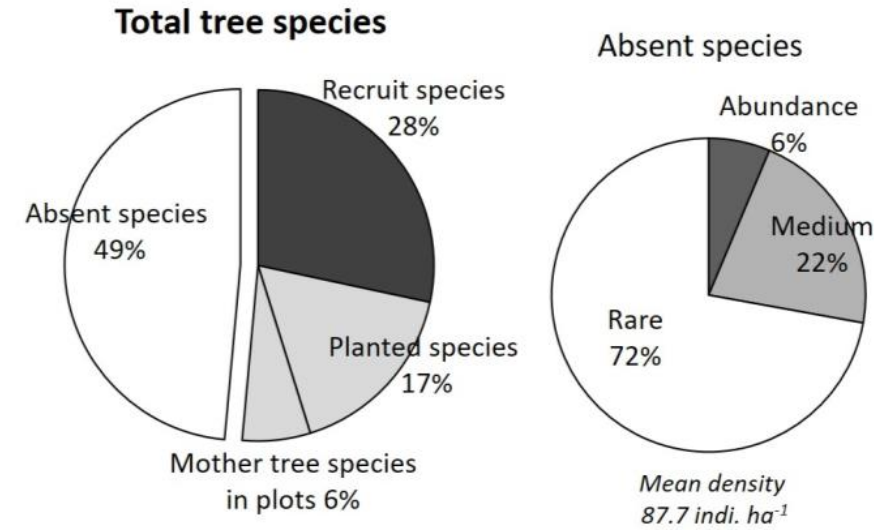

Recruit species

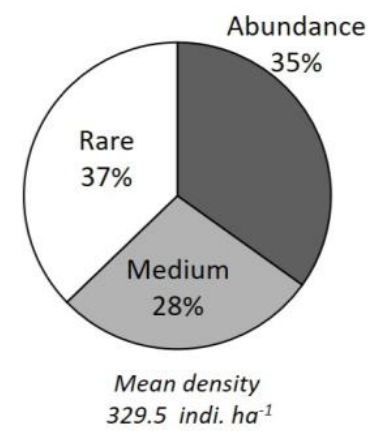

Figure 2. Percentage of tree species recorded in the adult tree survey that were present (recruit, planted, and mother tree species) or absent from seedling community of the R forest (data combined across all plot ages and censuses) and the percent of abundance, medium abundance and rare species with mean density (individuals per ha- ${ }^{-1}$ ) of absent species and recruit species.

Considering species that absent from the $\mathrm{R}$ plots, most of them belong to species that adult 
seed trees were less common or rare in the neighbourhood (Figure 2). Comparing among absent and recruit species, proportion of rare adult trees species that absent from the $\mathrm{R}$ plots was significantly larger than those recruited in the R plots (Chi square- $\chi^{2}=16.56$ or $p$-values $<001$ in Figure 2). In this study, several absent species were found with only one individual such as Brassaiopsis ficifolia Dunn, Celtis tetrandra Roxb., Dipterocarpus turbinatus C.F. Gaertn, and Goniothalamus laoticus (Finet \& Gagnep.) Bân. The mean population density of adult trees species that successfully recruited into the seedling communities of the $R$ plots was 329.7 individuals per ha, whilst that of absent species was only 87.7 individuals per ha. Most common species that recruited in the $R$ plots were Litsea salicifolia (Roxburgh ex Nees) Hook. $f$. and Artocarpus lacucha Buch.-Ham. ex D.Don. Moreover, many of the FWS planted in the R plots were common species in this area such as Machilus gamblei King ex Hook. f., Phoebe lanceolata (Nees) Nees, Castanopsis diversifolia (Kurz) King ex Hook.f., and Styrax benzoides Craib etc.

Table 1. Species richness and diversity index of adult tree species, and species found in seedling community of overall restoration plots

\begin{tabular}{lccc}
\hline & \multirow{2}{*}{$\begin{array}{c}\text { Overall adult tree } \\
\text { species }\end{array}$} & Recruited species & $\begin{array}{c}\text { Recruited species } \\
\text { plus FWS species }\end{array}$ \\
\cline { 3 - 4 } & 208 & 59 & 107 \\
\hline Species richness & & & \\
Species diversity & 0.981 & 0.911 & 0.635 \\
$\quad$ Simpson index (1-D) & 4.438 & 2.843 & 1.516 \\
Shannon index (H) & 0.407 & 0.291 & 0.043 \\
Evenness $\left(\mathrm{e}^{\mathrm{H} / \mathrm{s}}\right)$ & & &
\end{tabular}

For the factor of seed-dispersal agents, most of the adult tree species were animaldispersed $(74 \%, 154$ spp.), followed by non-animal-dispersed $(23 \%, 48 \mathrm{spp}$.$) and species that$ dispersal agent were unknown was 3\% (6 spp.) (Figure 3). Considering within the dispersal group, the percent recruit or absent from the seedling community of the $\mathrm{R}$ plots was not significant difference (Chi square- $\chi^{2}=0.6494$ or $p$-values $=0.420$ ). For the recruit native species, both nonanimal and animal-dispersed species recruited at the similar percentage $31 \%$ and $29 \%$ of total species, respectively. The planted species (including mother trees in plots) had their part $22 \%$ of animal-dispersed and $29 \%$ of non-animal-dispersed species in the seedling community.

\section{Total adult tree species}
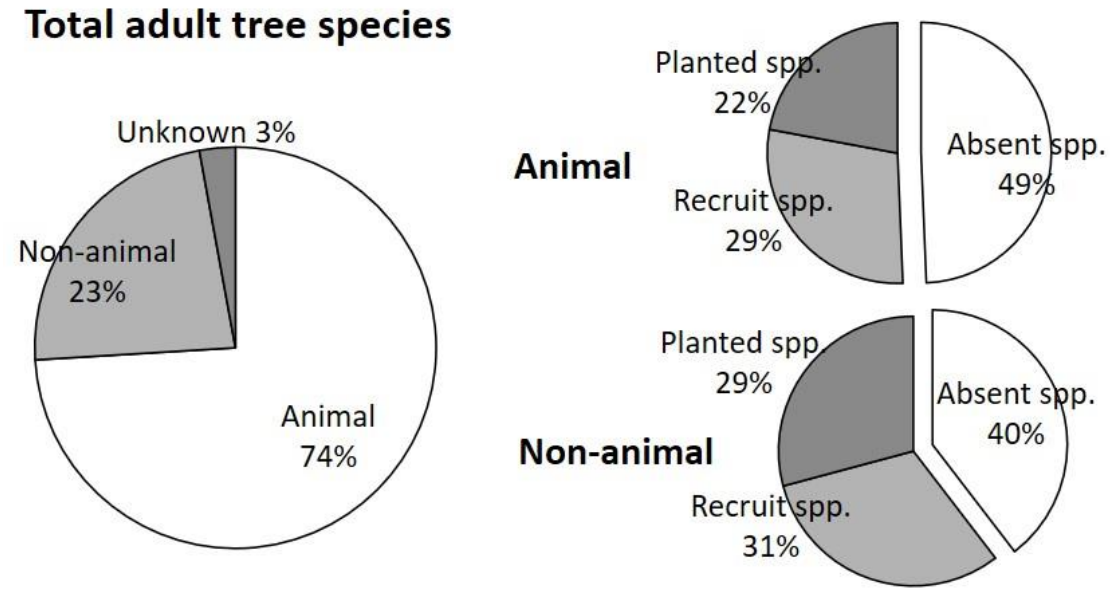

Figure 3. Percent species of seed-dispersal agents from total adult species and species that absent, recruit, and planted of each animal-dispersed and non-animal-dispersed agent 
As for seed size, most of tree species in the vicinity of the plots were small-seeded ( $60 \%$ of total adult species, $125 \mathrm{spp}$.) followed by medium-seeded (26\%, $53 \mathrm{spp}$.) and big-seeded species (11\%, $23 \mathrm{spp}$.) (Figure 7). Within all seed size categories, about half of the species (41-52\%) failed to recruit in the restoration plots. The proportion of big-seeded species that were absent or present in the $\mathrm{R}$ forests was significantly different from that of small-seeded species ( $p$-value $=0.0249$ by the Tukey test). This result might imply limitation of big-seeded species (with the absent percentage of $52 \%$ ) to recruit into the $\mathrm{R}$ forests.
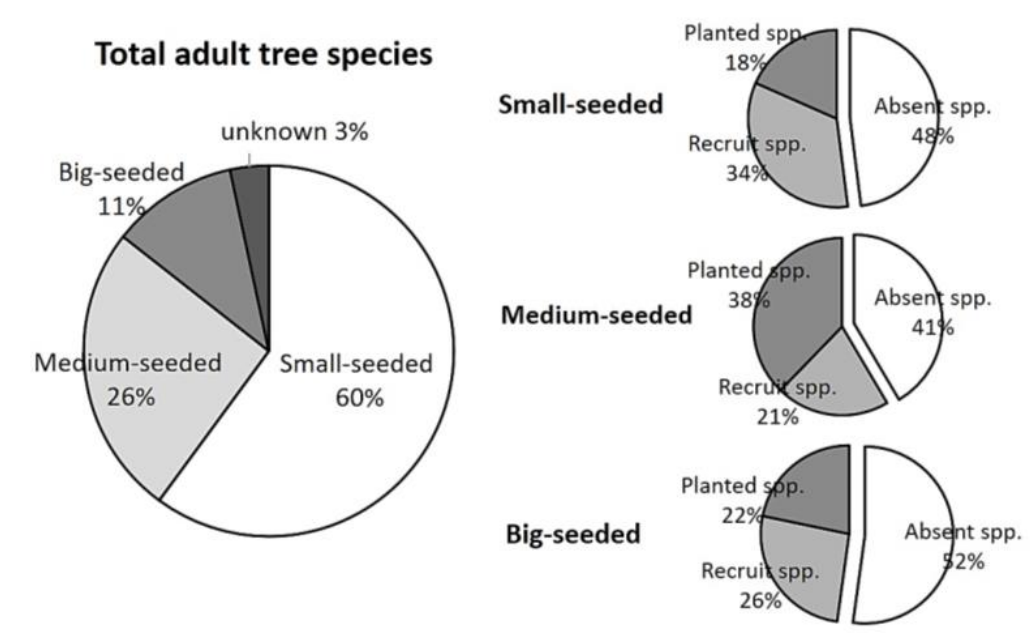

Figure 4. Percent species of each seed size from total adult species and percent absent, recruit, and planted species for each seed size

\subsection{Seedling recruitment among restoration ages}

Age of restoration was not a factor affecting the recruitment rate of the native tree species into seedling community of the restoration forest. Seedlings recruitment rate of native tree species did not significantly differ among 3 restoration ages ( $p$-value $\geq 0.052$ by Mann-Whitney test in Figure 5 ). For species recruitment rate, new species that recruit in seedling community of the R plots was very low from $6 \%$ to $30 \%$ per year. Seedlings of recruited species Micromelum integerrimum var. intergerrimum and Litsea salicifolia, which were small-seeded animal-dispersed species, dominated abundantly (over 80 individuals per $\mathrm{m}^{2}$ ) in the R10 and R14 plots but quite rare (less than 10 individuals) in the youngest R6 plots. Whilst, the most abundant species in the R6 plots was Artocarpus nitidus, however, this species was a common in the R14 plots as well. The Whittaker $\beta$ diversity index indicates similarity of recruited species among all the restoration ages with the index ranged from 0.373 to 0.491 unit.

Similar to large component of animal-dispersed and small-seeded species found in seed source, most seedlings and species of native tree species that recruit in seedling community of the all 3 restoration ages majorly belong to animal-dispersed small-seeded species. In the R6 plots, percentage of animal-dispersed species was significantly higher than that in the R14 plots (Chi square- $\chi^{2}=10.051$ or $p$-value $=0.0015$ in Figure 6 ) whilst the percentage in the R10 plots was ranked in the middle. However, seedlings of animal-dispersed species with very high percentage (over $80 \%$ ) outnumbered that of the non-animal-dispersed species in all 3 ages of restoration. Accordingly, percentage of seedlings among two dispersal agents did not differ significantly with plot age (Chi square- $\chi^{2} \leq 3.724$ or $p$-value $<0.05$ in Figure 6 ). 


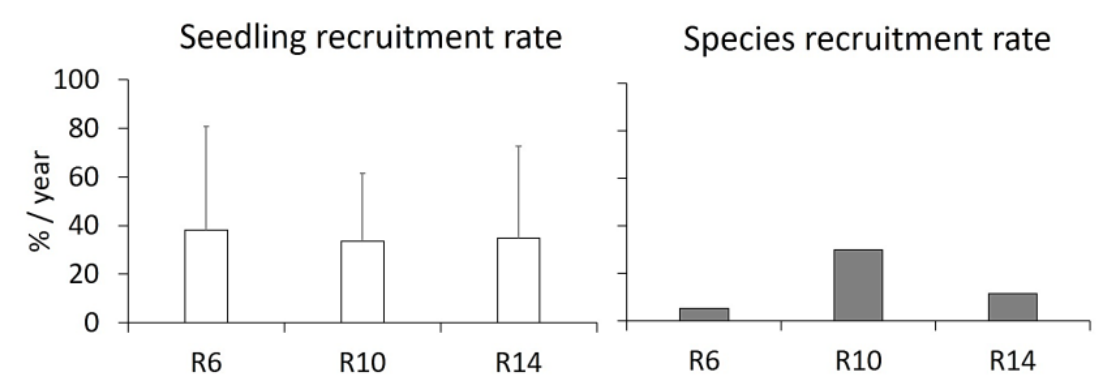

Figure 5. The recruitment rate (\% per year) of native tree species for recruit seedlings with standard deviation and recruit species in each 3 age of FWS restoration

As for seed sizes, according to large proportion of small-seeded species in the seed pool, most of recruit native species across all 3 ages were small-seeded species as well. Percent species of bigseeded species slightly increased with plot age, but not significantly (Chi square- $\chi^{2} \leq 0.809$ or $p$-value $<0.10$ in Figure 6). Considering seedling individuals, the percent of seedlings recorded of mediumseeded species in the R6 plots was significantly higher than in the other forest plots (Chi square- $\chi^{2} \geq$ 19.753 or $p$-value $>0.001$ in Figure 6 ). This result was a consequent of forty-five out of forty-seven seedlings belonged to a single species: Artocarpus nitidus (seed-size $=3.73 \mathrm{~mm}^{3}$ ), due to the close proximity of a fruiting tree of this species to the R6 plots.

The Principle Component Analysis (PCA) shows slightly correlation among seed sizes and dispersal agents of the recruit species (Figure 6). Animal-dispersed species had positive correlation with all sizes of seed, whilst, non-animals-dispersed species had positive correlation only with smallseeded species. Among the restoration ages, there was no distinctive characteristic of species recruited in seedling community of all restoration ages.

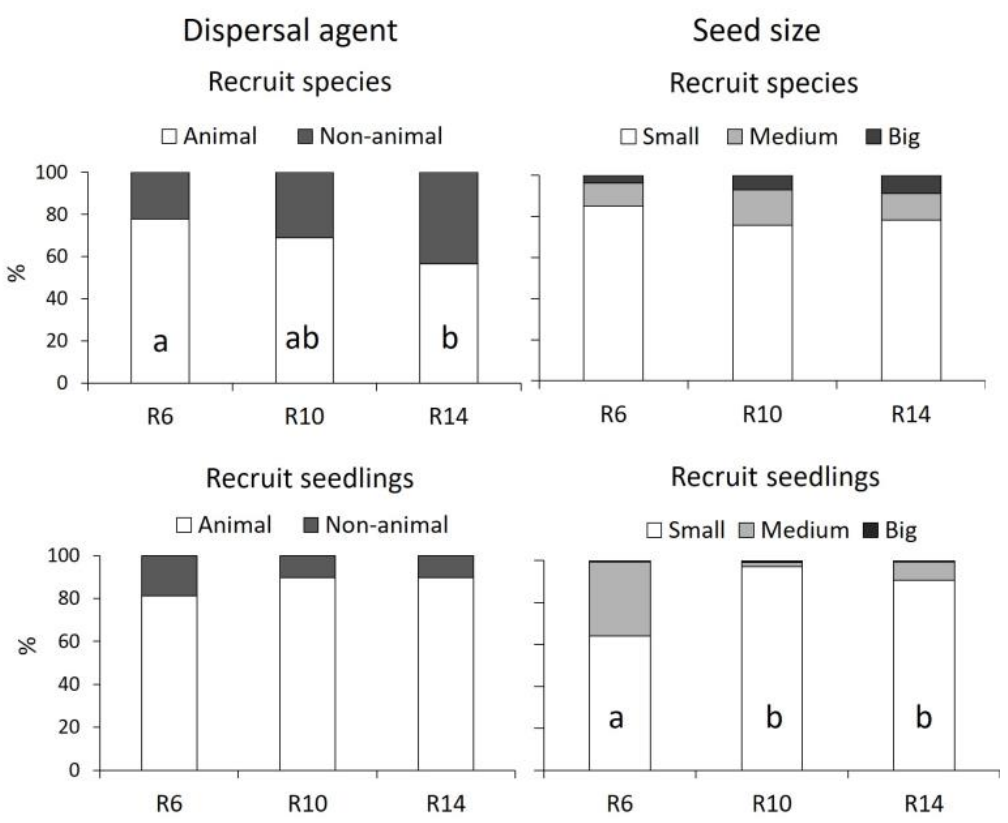

Figure 6. Percentage seed-dispersal agents and seed sizes of recruit native species and recruit seedlings found in seedling community of each restoration age. Different letters indicate significant differences in Chi-square test $\left(\chi^{2}\right)$ among restoration ages. 


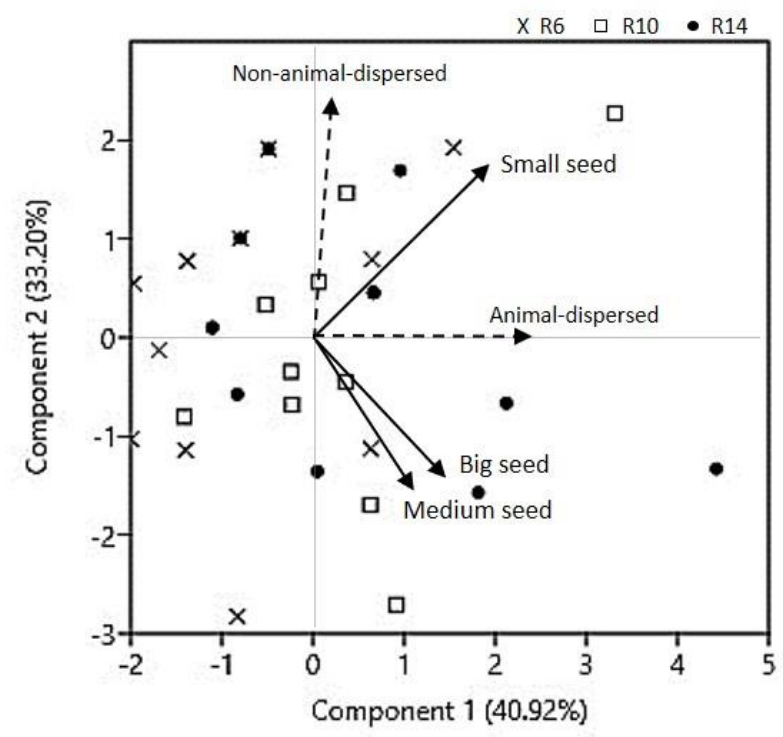

Figure 7. Principle Component Analysis (PCA) for the correlation of functions (seed sizes and dispersal agents) of recruited species in the restoration plots R6, R10, and R14 ( $n=12$ ).

\section{Discussion}

Seed available was a primary factor limiting seeds reaching to the restoration sites. About half of native species, in the nearby seed pool, failed to recruit and establish in the active restoration by the FWS technique. One of the reasons may have been because they were less common or rarer in the surrounding landscape. This result supports the previous experiment in same study sites of BMSM restoration forests by Sansupan et al. (2018) who reported that lack of seed availability or inadequate seed dispersal limit tree species to colonize. Similar result also found in the secondary forest by Chen et al. 2014. Contrary to expectation that seed-dispersal limit seedling recruitment in regeneration sites (Dalling et al. 2002, De Souza and Batista 2004; Asanok et al. 2013; Chen et al. 2014), seed-dispersed agents did not appear to a limited factor due to similar percentage of all seeddispersed agents recruit and establish in the seedling community of the overall FWS restoration. The result shows a sign of big-seeded limitation from the seed source to recruit in the restoration site. This result is in accordance with a study by Reid et al (2015) who reported large seed species were limit in the study of seed rain in the restoration area. The recruitment of big-seeded species found in the restoration site age over 10 year might imply seed-dispersal agents of those big-seeded species could visit and/or be attracted into the restoration site and seed-dispersal agents remained common in the landscape (as evidenced by camera trapping, carried out by FORRU-CMU, unpublished observations).

Seedling recruitment in plantations strongly depends on seeds from neighbouring sites (Farwig et al. 2009). Similarly, most of adult tree species found in the nearby natural remnant forest belong to animal-dispersed, small-seeded species. Consequently, these dominance of such species in natural forest were reflected by seedling community of native species that recruited in the FWS restoration forests. Although percent species of non-animal-dispersed agent seems to increase with restoration age, seedlings of animal-dispersed recruited in large quantity in all 3 ages forests. This result agrees with a previous study in Costa Rica (Cusack and Montagnini 2004) and support the finding of FWS trees attracting animal disperser into the restoration area by Wydhayagarn et al. (2009).

Along with Viani et al. (2015), older age of restoration shows slightly higher percentage seedlings of animal-dispersed species but was not significantly different. The reason might be 
explained by similarly rate of seedling recruitment rate. The comparison among restoration ages reveals a similarity of seedling recruitment rate of native tree species. The FWS restoration from 6 to 14 years supported seedling of native tree species to recruit and establish in a similar manner. However, the low species recruitment rate might project similar cohort of native species that able to disperse from seed source to neighbourhood area which half of them yet to recruit. In Costa Rica, Capers et al. (2005) reported that it takes at least 30 years after pasture abandonment for seedlings of rare tree species to become well established, since most of them have large, animal-dispersed seeds. Tabarelli and Peres (2002) reported that plant species, dispersed by vertebrates, gradually increase with plot age. In accordance with Capers et al. (2005), although there was a sign of bigseeded species occurred to a slightly extend in 10-14-year-old forests than in 6-year-old forest, the differences among ages were insignificant. Due to the oldest age of the FWS restoration was 14 years in this study, these results might be an initial sign of higher attractive potential of big-seeded species in $>10$-year-old than young-age forests.

In addition, planted trees and mother trees that were left from deforestation had their part filling the gap of species recruitment in seedling community, especially medium- and big-seeded species. However, the effectiveness of the technique is limited by the availability of mature seed tree species. Regard of seed available, tree species that are less common or rare in the surrounding landscape might be selected or mixed as one of the planted framework species to enhance diversity, since these rare species are unlikely to recruit without such intervention. Accordingly, species that are abundance or common in the restoration area might be excluded or less planted as the FWS. However, knowledge of seed-tree abundance in areas around restoration sites could help restoration manager to design what species are needed in order for best outcome of forest restoration.

\section{Conclusions}

A major limitation for native tree species to recruit in the active restoration by the FWS technique was seed trees availability. Big-seeded species had higher change unable to reach and establish in the seedling community of the restoration site than small-seeded species, whilst, the limitation of seed-dispersed agents did not affect the recruitment in this study. Although there were none significant of large-seeded species enhanced by restoration age, the slightly higher seedlings of large-seeded species in 10-14-year-old forests might be an initial sign of attracting more seedlings of these species in the future. The planted FWS trees had their important part as mother trees providing seedlings of all kind of seed sizes and dispersed agents adding into seedling community, however, this restoration technique was limited by the lack of seed availability to attract more recruit native species into the area. Since most of the FWS are common native species, species that are less common or rarer in the seed pool might be included as the planted species in order to enhance species diversity. The restoration forest should be carefully planned. Preliminary study or observation for possible seed species abundance in the restoration area could help the manager plan and design what technique and how to restored the forest for uttermost benefit and outcome in the future.

\section{Acknowledgments}

This research was fund by National Science and Technology Development (NSTDA) [code no. P-1300571]. The author thanks FORRU-CMU, Dr. Stephen Elliott, Assoc. Prof. Prasit Wangpakapattanawong, Asst. Prof. Dr. Sutthathorn Chairuangsri, and Department of Biology, Faculty of Science, Chiang Mai University for providing equipment and facility, Dr. Wattana Tanming, Mr. James F. Maxwell, Khun Neng, and every FORRU's interns from Maejo University for helping with field work. 


\section{Conflicts of interest}

The authors declare no conflict of interest.

\section{References}

Ashton, M. S., Gunatilleke, C. V. S., Singhakumara, B. M. P., \& Gunatilleke, I. A. U. N. (2001). Restoration pathways for rain forest in southwest Sri Lanka: a review of concepts and models. Forest Ecology and Management, 154(3), 409-430. doi: https://doi.org/10.1016/S0378-1127(01)00512-6

Asanok, L., Marod, D., Duengkae, P., Pranmongkol, U., Kurokawa, H., Aiba, M., ... \& Nakashizuka, T. (2013). Relationships between functional traits and the ability of forest tree species to reestablish in secondary forest and enrichment plantations in the uplands of northern Thailand. Forest and ecology management, 296, 9-23. doi: https://doi.org/10.1016/j.foreco.2013.01.029

Brodie, J. F. (2007). Effects of seed dispersal by gibbons, sambar, and muntjac on Choerospondias axillaris demography, and the disruption of this mutualism by wildlife poaching [Doctoral dissertation]: University of Montana.

Corlett, R. T., \& Hau, B. C. (2000). Seed dispersal and forest restoration. Forest restoration for wildlife conservation, 317-325.

Capers, R. S., Chazdon, R. L., Brenes, A. R., \& Alvarado, B. V. (2005). Successional dynamics of woody seedling communities in wet tropical secondary forests. Journal of Ecology, 93(6), 1071-1084. doi: https://doi.org/10.1111/j.1365-2745.2005.01050.x

Chazdon, R. L. (2014). Second growth: the promise of tropical forest regeneration in an age of deforestation. University of Chicago Press.

Chen, L., Wang, L., Baiketuerhan, Y., Zhang, C., Zhao, X., \& von Gadow, K. (2014). Seed dispersal and seedling recruitment of trees at different successional stages in a temperate forest in northeastern China. Journal of Plant Ecology, 7(4), 337-346. doi: https://doi.org/10.1093/jpe/rtt024

Cusack, D., \& Montagnini, F. (2004). The role of native species plantations in recovery of understory woody diversity in degraded pasturelands of Costa Rica. Forest Ecology and management, 188(1-3), 1-15. doi: https://doi.org/10.1016/S0378-1127(03)00302-5

Dalling, J. W., Muller-Landau, H. C., Wright, S. J., \& Hubbell, S. P. (2002). Role of dispersal in the recruitment limitation of neotropical pioneer species. Journal of Ecology, 90(4), 714-727. doi: https://doi.org/10.1046/j.1365-2745.2002.00706.x

de Souza, F. M., \& Batista, J. L. F. (2004). Restoration of seasonal semideciduous forests in Brazil: influence of age and restoration design on forest structure. Forest ecology and Management, 191(1-3), 185-200. doi: https://doi.org/10.1016/j.foreco.2003.12.006

eFloras. (2014). Flora of China, Missouri Botanical Garden, St. Louis, MO \& Harvard University Herbaria, Cambridge, MA. March 2014] http://www.efloras.org/flora_page.aspx?flora_id=2

Elliott, S., Navakitbumrung, P., Kuarak, C., Zangkum, S., Anusarnsunthorn, V., \& Blakesley, D. (2003). Selecting framework tree species for restoring seasonally dry tropical forests in northern Thailand based on field performance. Forest Ecology and Management, 184(1-3), 177-191. doi: https://doi.org/10.1016/S0378-1127(03)00211-1

Eshetu, E. Y. (2002). Restoration of the native woody-species diversity, using plantation species as foster trees, in the degraded highlands of Ethiopia [Doctoral dissertation]: University of Helsinki, Viikki Tropical Resources Institute (VITRI).

FAO. (2010). Global forest resources assessment 2010: country report, Thailand. FAO Forestry Department, Food and Agriculture Organization of the United Nations. Retrieved from http://www.fao.org/forestry/fra/67090/en/tha/ 
Farwig, N., Sajita, N., \& Böhning-Gaese, K. (2009). High seedling recruitment of indigenous tree species in forest plantations in Kakamega Forest, western Kenya. Forest ecology and management, 257(1), 143-150. doi: https://doi.org/10.1016/j.foreco.2008.08.02

FORRU. (2005). How to Plant a Forest: The Principles and. Practice of Restoring Tropical Forests. Biology Department, Science Faculty, Chiang Mai University, Thailand. Retrieved from http://www.forru.org/extra/forru/PDF_Files/htpafbook/htpafbook.pdf

FORRU. 2008. Research for Restoring Tropical Forest Ecosystems: A Practical Guide. Biology Department, Science Faculty, Chiang Mai University, Thailand. Retrieved from http://www.forru.org/extra/forru/PDF_Files/rfrtfpdf/RFRTFIQ.pdf

Gomes, E. P. C., Mantovani, W., \& Kageyama, P. Y. (2003). Mortality and recruitment of trees in a secondary montane rain forest in southeastern Brazil. Brazilian Journal of Biology, 63(1), 47-60. doi: https://doi.org/10.1590/S1519-69842003000100007

Hammer, Ø., \& Harper. D.A. (2008). Paleontological data analysis. John Wiley \& Sons. USA.

Hammer, Ø., Harper, D. A., \& Ryan, P. D. (2001). PAST: Paleontological statistics software package for education and data analysis. Palaeontologia electronica, 4(1), 9.

Kaewkrom, P., Gajaseni, J., Jordan, C. F., \& Gajaseni, N. (2005). Floristic regeneration in five types of teak plantations in Thailand. Forest Ecology and Management, 210(1-3), 351-361. doi: https://doi.org/10.1016/j.foreco.2005.02.048

Koonkhunthod, N., Sakurai, K., \& Tanaka, S. (2007). Composition and diversity of woody regeneration in a 37-year-old teak (Tectona grandis L.) plantation in Northern Thailand. Forest Ecology and Management, 247(1-3), 246-254. doi: https://doi.org/10.1016/j.foreco.2007.04.053

Maxwell, J. F., \& Elliot, S. (2001). Vegetation and vascular flora of Doi Sutep-Pui national park, Northern Thailand (No. 5). Biodiversity Research and Training Program.

Meers, T. L., Enright, N. J., Bell, T. L., \& Kasel, S. (2012). Deforestation strongly affects soil seed banks in eucalypt forests: generalisations in functional traits and implications for restoration. Forest ecology and management, 266, 94-107. doi: https://doi.org/10.1016/j.foreco.2011.11.004

Oberhauser, U. (1997). Secondary forest regeneration beneath pine (Pinus kesiya) plantations in the northern Thai highlands: a chronosequence study. Forest Ecology and Management, 99(1-2), 171-183. doi: https://doi.org/10.1016/S0378-1127(97)00203-X

Reid, J. L., Holl, K. D., \& Zahawi, R. A. (2015). Seed dispersal limitations shift over time in tropical forest restoration. Ecological Applications, 25(4), 1072-1082. doi: https://doi.org/10.1890/141399.1

Sangsupan, H. A., Hibbs, D. E., Withrow-Robinson, B. A., \& Elliott, S. (2018). Seed and microsite limitations of large-seeded, zoochorous trees in tropical forest restoration plantations in northern Thailand. Forest Ecology and Management, 419, 91-100. doi: https://doi.org/10.1016/j.foreco.2018.03.021

Sheil, D., \& May, R. M. (1996). Mortality and recruitment rate evaluations in heterogeneous tropical forests. Journal of ecology, 91-100. doi: 10.2307/2261703 https://www.jstor.org/stable/2261703

Sinhaseni, K. (2008). Natural establishment of tree seedling in forest restoration trials at Ban Mae Sa mai, Chiang Mai Province. [master's thesis]: Chiang Mai University. Thailand.

Tabarelli, M., \& Peres, C. A. (2002). Abiotic and vertebrate seed dispersal in the Brazilian Atlantic forest: implications for forest regeneration. Biological Conservation, 106(2), 165-176. doi: https://doi.org/10.1016/S0006-3207(01)00243-9

Tucker, N. I., \& Murphy, T. M. (1997). The effects of ecological rehabilitation on vegetation recruitment: some observations from the Wet Tropics of North Queensland. Forest ecology and management, 99(1-2), 133-152. doi: https://doi.org/10.1016/S0378-1127(97)00200-4

Viani, R. A. G., Vidas, N. B., Pardi, M. M., Castro, D. C. V., Gusson, E., \& Brancalion, P. H. (2015). Animal-dispersed pioneer trees enhance the early regeneration in Atlantic Forest restoration 
plantations. Natureza \& Conservação, 13(1), 41-46. doi: https://doi.org/10.1016/j.ncon.2015.03.005

Wydhayagarn, C., Elliott, S., \& Wangpakapattanawong, P. (2009). Bird communities and seedling recruitment in restoring seasonally dry forest using the framework species method in Northern Thailand. New Forests, 38(1), 81-97. doi: https://doi.org/10.1007/s11056-009-9133-z 